\title{
Plasma cell and terminal B-cell differentiation in mantle cell lymphoma mainly occur in the SOX11-negative subtype
}

Inmaculada Ribera-Cortada ${ }^{1,2}$, Daniel Martinez ${ }^{1}$, Virginia Amador ${ }^{3}$, Cristina Royo ${ }^{3}$, Alba Navarro ${ }^{3}$, Silvia Beà ${ }^{3}$, Eva Gine ${ }^{3,4}$, Laurence de Leval ${ }^{5}$, Sergio Serrano ${ }^{6}$, Andrew Wotherspoon ${ }^{7}$, Dolors Colomer ${ }^{1,3}$, Antonio Martinez ${ }^{1,3}$ and Elías Campo ${ }^{1,3}$

${ }^{1}$ Hematopathology Unit, Department of Anatomic Pathology, Hospital Clinic, University of Barcelona, Barcelona, Spain; ${ }^{2}$ Hospital Nostra Senyora de Meritxell, Escaldes-Engordany, Principat d'Andorra; ${ }^{3}$ Institut d'Investigacions Biomèdiques August Pi i Sunyer (IDIBAPS), Barcelona, Spain; ${ }^{4}$ Department of Hematology, Hospital Clinic, University of Barcelona, Barcelona, Spain; ${ }^{5}$ Institute of Pathology, Centre Hospitalier Universitaire Vaudois, Lausanne, Switzerland; ${ }^{6}$ Department of Pathology, Hospital del Mar, Autonomous University of Barcelona, Barcelona, Spain and ${ }^{7}$ Department of Histopathology,

Royal Marsden Hospital, London, UK

Mantle cell lymphoma is a mature lymphoid neoplasm characterized by the $t(11 ; 14)(q 13 ; q 32)$ and cyclin D1 overexpression. SOX11 is a transcription factor commonly overexpressed in these tumors but absent in most other mature B-cell lymphomas whose function is not well understood. Experimental studies have shown that silencing of SoX11 in mantle cell lymphoma cells promotes the shift from a mature B cell into an early plasmacytic differentiation phenotype, suggesting that SOX11 may contribute to tumor development by blocking the B-cell differentiation program. The relationship between SOX11 expression and terminal B-cell differentiation in primary mantle cell lymphoma and its relationship to the plasmacytic differentiation observed in occasional cases is not known. In this study we have investigated the terminal B-cell differentiation phenotype in 60 mantle cell lymphomas, 41 SOX11-positive and 19 SOX11-negative. Monotypic plasma cells and lymphoid cells with plasmacytic differentiation expressing cyclin D1 were observed in $7(37 \%)$ sox11-negative but in none of 41 SOX11-positive mantle cell lymphomas $(P<0.001)$. Intense cytoplasmic expression of a restricted immunoglobulin light chain was significantly more frequent in SOX11-negative than -positive tumors (58 vs $13 \%)(P=0.001)$. Similarly, BLIMP1 and XBP1 expression was also significantly more frequent in SOX11-negative than in -positive cases ( 83 vs $34 \%$ and 75 vs $11 \%$, respectively) $(P=0.001)$. However, no differences in the expression of IRF4/MUM1 were observed among these subtypes of mantle cell lymphoma. In conclusion, these results indicate that SOX11negative mantle cell lymphoma may be a particular subtype of this tumor characterized by more frequent morphological and immunophenotypic terminal B-cell differentiation features that may be facilitated by the absence of SOX11 transcription factor.

Modern Pathology (2015) 28, 1435-1447; doi:10.1038/modpathol.2015.99; published online 11 September 2015

Mantle cell lymphoma is a mature B-cell neoplasm genetically characterized by the $t(11 ; 14)(q 13 ; q 32)$ leading to the overexpression of cyclin $\mathrm{D} 1 .^{1}$ Other mechanisms involved in the progression of these tumors include alterations in components of the cell cycle regulation, DNA damage response, and apoptotic pathways. ${ }^{1}$ SOX11 is a transcription factor

Correspondence: Dr E Campo, MD, PhD, Hematopathology Unit, Department of Anatomic Pathology, Hospital Clinic, University of Barcelona, Villarroel 170, 080136 Barcelona, Spain.

E-mail: ECAMPO@clinic.ub.es

Received 20 May 2015; accepted 15 July 2015; published online 11 September 2015 overexpressed in the vast majority of mantle cell lymphoma, including cyclin D1-negative cases, but it is absent in most other mature B-cell lymphomas, with the exception of some Burkitt lymphomas. ${ }^{2-6}$ The potential implication of SOX11 in the aggressive behavior of mantle cell lymphoma was initially suggested when it was recognized as one of the genes highly expressed in tumors requiring treatment at diagnosis compared with cases with a very indolent clinical course. ${ }^{7}$ The relationship between the absence of SOX11 expression and an indolent clinical behavior of these tumors has been confirmed in subsequent studies $^{8-10}$ but not in others. ${ }^{11}$ 
However, most aggressive SOX11-negative mantle cell lymphoma carry also TP53 mutations and may, therefore, correspond to a transformed form of these tumors. ${ }^{10,11}$ The oncogenic potential of SOX11 has been confirmed experimentally by SOX11knockdown studies that have shown a significant reduction of tumor growth in vivo of xenografted SOX11-negative mantle cell lymphoma cell lines. ${ }^{12,13}$

The oncogenic mechanisms of SOX11 in mantle cell lymphoma pathogenesis are not well understood. We have recently shown that PAX5 is one of the genes directly regulated by SOX11 in these tumor cells. ${ }^{13}$ PAX5 is a critical transcription factor that determines and maintains the B-cell identity by activating B-cellspecific genes and simultaneously repressing genes that promote plasma cell differentiation. ${ }^{14-16}$ SOX11 knockdown in mantle cell lymphoma cell lines resulted in PAX5 downregulation, increased expression of BLIMP1 and XBP1 and a switch in the gene expression signatures from a mature B-cell to an early plasmacytic differentiation profiling. ${ }^{13}$ These findings suggested that SOX11 could contribute to mantle cell lymphoma lymphomagenesis by blocking the terminal B-cell differentiation program of the cells as a similar mechanism observed in the inactivating mutations of PRDM1/BLIMP1 in diffuse large B-cell lymphoma or the forced expression of $P A X 5$ by the $t$ $(9 ; 14)(p 13 ; q 32)$ in some B-cell lymphomas. ${ }^{17-19}$ However, whether primary mantle cell lymphoma may modulate terminal B-cell differentiation features in relation to SOX11 expression is not well known.

The presence of plasmacytic differentiation is the defining feature of lymphoplasmacytic lymphomas ${ }^{20}$ but a certain degree of this differentiation may also occur in other small B-cell lymphoid neoplasms such as chronic lymphocytic leukemia, follicular lymphoma, or marginal zone lymphoma. ${ }^{21-23}$ Recently, the L265P MYD88 mutation has been recognized as very characteristic of Waldenström macroglobulinemia/lymphoplasmacytic lymphoma. ${ }^{24}$ Although this mutation may also be present in other lymphoid tumors such as diffuse large B-cell lymphoma, chronic lymphocytic leukemia and occasional marginal zone lymphoma, it has not been observed in mantle cell lymphoma. ${ }^{25-28}$ The majority of mantle cell lymphoma have been classically described as a monotonous population of mature B cells without evidence of plasmacytic differentiation. ${ }^{29}$ However, occasional mantle cell lymphomas with focal areas of plasma cell differentiation have been reported. ${ }^{30-32}$ These studies have emphasized the presence of mature clonally related plasma cells in otherwise classical mantle cell lymphoma but the potential relationship to SOX11 expression is not known. On the other hand, the expression of transcription factors regulating the switch from mature B-cell to plasma cells such BLIMP1, IRF4/MUM1 and XBP1 have not been well investigated in these tumors. Recognizing terminal B-cell differentiation in mantle cell lymphoma may be important in the differential diagnosis with other
B-cell neoplasms expressing this phenotype. In addition, the recent observation relating the resistance of mantle cell lymphoma to bortezomib, a drug with promising results in the treatment of these patients, to the development of an early plasmacytic differentiation ${ }^{33}$ suggests that understanding this phenomenon may have also therapeutic relevance. The aims of this study were to determine the presence of terminal B-cell differentiation characteristics in mantle cell lymphoma and their possible relationship WITH SOX11 expression.

\section{Materials and methods}

\section{Samples and Patients}

We have included in the study 60 mantle cell lymphoma patients retrieved from the files of the Laboratory of Pathology of the Hospital Clinic of Barcelona based on the availability of formalin-fixed paraffin-embedded tissue for immunohistochemical studies. All cases overexpressed cyclin D1 by immunohistochemistry and in 18 cases the $t(11 ; 14)(q 13$; q32) had been confirmed by conventional cytogenetic or FISH studies. One case had been included in the previous study by Visco et al ${ }^{32}$ (Case 6). SOX11 nuclear protein was expressed in 41 cases, whereas 19 were SOX11-negative. SOX11 mRNA expression was also investigated by quantitative PCR in 23 mantle cell lymphoma cases, 15 SOX11-positive and 8 SOX11-negative and mRNA levels correlated to SOX11 protein expression as previously described. ${ }^{34}$ The tissues investigated in the SOX11-positive cases were lymph nodes $(29,71 \%)$, spleen $(5,12 \%)$, spleen and lymph nodes $(3,7 \%)$, and other extranodal sites $(4,10 \%)$, whereas in the SOX11-negative cases were lymph nodes $(3,16 \%)$, spleen $(10,53 \%)$, spleen and lymph nodes $(5,26 \%)$, and other extranodal site $(1,5 \%)$.

\section{Immunohistochemistry}

Immunohistochemistry was performed on formalinfixed paraffin-embedded material. The staining for cyclin D1, CD5, IRF4/MUM1, CD20, CD3, BLIMP1, PAX5, kappa, and lambda light chains were developed in an automated immunostainer (AutostainerLink 48 DAKO). Antigen retrieval was done for 20 min in Envision Flex TRS High pH (pH 9, DAKO) or Low $\mathrm{pH}$ (pH6, DAKO) buffer solution at $98^{\circ} \mathrm{C}$ accordingly. The primary antibodies, monoclonal rabbit anti-human cyclin D1 clone SP4 (Ready to Use DAKO), monoclonal rabbit anti-human CD5 clone SP19 (Ready to Use, DAKO), monoclonal mouse anti-human MUM1-protein clone MUM1p (Ready to Use, DAKO), monoclonal mouse anti-human CD20 clone L26 (Ready to Use DAKO), monoclonal mouse anti-human CD3 clone CD3-PS1 (diluted 1:60 Novocastra), monoclonal mouse anti-human BLIMP1 antibody provided by Dr G Roncador (Centro Nacional Investigaciones Oncologicas diluted 1:3), 
Table 1 Clinical and pathological characteristics of the 60 mantle cell lymphomas

\begin{tabular}{|c|c|c|c|}
\hline Patients & $\begin{array}{c}\text { SOX11-negative mantle } \\
\text { cell lymphoma } \\
\mathrm{n}=19\end{array}$ & $\begin{array}{c}\text { SOX11-positive mantle } \\
\text { cell lymphoma } \\
\mathrm{n}=41\end{array}$ & $\mathrm{P}$-value \\
\hline No. & 19 & 41 & \\
\hline Median age, years (range) & $72(53-80)$ & $64(42-89)$ & \\
\hline Male & $10 / 19(53 \%)$ & $38 / 41(93 \%)$ & 0.001 \\
\hline CD5 expression & $12 / 18(67 \%)$ & $35 / 36(97 \%)$ & 0.002 \\
\hline \multicolumn{4}{|l|}{ Histology } \\
\hline Small cell & $11 / 19(58 \%)$ & $1 / 41(2 \%)$ & $<0.001$ \\
\hline Classic & $7 / 19(37 \%)$ & $33 / 41(81 \%)$ & 0.002 \\
\hline Blastoid/pleomorphic & $1 / 19(5 \%)$ & $7 / 41(17 \%)$ & 0.211 \\
\hline Ki67 index mean \pm s.d. & $20 \pm$ s.d.18 & $34.5 \pm$ s.d. 23 & 0.017 \\
\hline \multicolumn{4}{|l|}{ Ann Arbor stage } \\
\hline I/III & $0 / 11(0 \%)$ & $3 / 28(11 \%)$ & \\
\hline IV & $11 / 11(100 \%)$ & $25 / 28(89 \%)$ & 0.258 \\
\hline LDH level > normal & $2 / 9(22 \%)$ & $10 / 22(45 \%)$ & 0.452 \\
\hline Mutated IGHV ( $<98 \%$ identity) & $7 / 11(64 \%)$ & $1 / 25(4 \%)$ & $<0.001$ \\
\hline Non-nodal presentation & $15 / 19(79 \%)$ & $8 / 41(20 \%)$ & $<0.001$ \\
\hline Leukemic involvement & 11/12 (92\%) & $21 / 28(75 \%)$ & 0.227 \\
\hline Bone marrow involvement & $11 / 11(100 \%)$ & $25 / 28(89 \%)$ & 0.258 \\
\hline \multicolumn{4}{|l|}{ Pathology } \\
\hline Plasma cell differentiation & 7/19 (37\%) & $0 / 41(0 \%)$ & $<0.001$ \\
\hline Cytoplasmic light-chain expression & $11 / 19(58 \%)$ & $5 / 39(13 \%)$ & 0.001 \\
\hline BLIMP1 expression & $15 / 18(83 \%)$ & $13 / 38(34 \%)$ & 0.001 \\
\hline MUM1 expression & $10 / 19(53 \%)$ & $18 / 40(45 \%)$ & 0.705 \\
\hline XBP1 expression & $12 / 16(75 \%)$ & $4 / 38(11 \%)$ & $<0.001$ \\
\hline \multicolumn{4}{|l|}{ Therapy } \\
\hline No chemotherapy & $9 / 14(64 \%)$ & $1 / 28(4 \%)$ & $<0.001$ \\
\hline Chemotherapy & $5 / 14(36 \%)$ & $27 / 28(96 \%)$ & $<0.001$ \\
\hline Median survival, range (months) & $103(64-141)$ & $44(24-64)$ & 0.024 \\
\hline
\end{tabular}

monoclonal mouse anti-human B Cell Specific Activator Protein Clone DAK-PAX5 (Ready to Use DAKO), polyclonal rabbit anti-human kappa light chain, and polyclonal rabbit anti-human lambda light chain (DAKO both diluted 1:128 000) were incubated followed by the secondary antibody Envision Flex Rabbit and Mouse linker, respectively. A peroxidasebased EnVision Flex/HRP system (DAKO) was used for the detection and 3,3'-diaminobenzidine as a chromogen. For SOX11 and XBP1, the slides were processed in a fully automated immunostainer (Bond Max, Vision Biosystems, Mount Waverley, Australia). The procedure was the same as described above. Antigen retrieval was done for $20 \mathrm{~min}$ in Bond ER Buffer solution ( $\mathrm{pH} 9$ and $\mathrm{pH}$ 6, Vision Biosystems, respectively). The primary antibodies were mouse monoclonal anti-SOX11 143 (AMAb90502, clone CL0143; Atlas Antibodies, Stockholm, Sweden at 1:100), rabbit polyclonal anti-SOX11 HPA000536 (HPA 000536, Atlas Antibodies, Stockholm, Sweden at 1:400 dilution) and mouse monoclonal anti-XBP1 (Santa Cruz diluted 1:400). Bond Refine Polymer (Vision Biosystems) was used as secondary antibody for detection.
Slides were reviewed, analyzed, and photographed on a Olympus BX51 microscope, by means of DP70 cooled CCD camera (Olympus) with the use of Cell^ $\wedge$ imaging software (Olympus). The antigen expression was considered positive if $\geq 10 \%$ of tumor cells showed strong positive staining. This quantitative index was obtained by counting the number of positive tumor cells within 200 tumor cells in a High Power Field $(\times 40)$ within a representative tumor area. The statistical analyses were performed using the SPSS software package version 21 (SPSS, Chicago, IL, USA).

\section{DNA Extraction and Assessment of MYD88 Mutation}

DNA was isolated with the QIAamp DNA mini kit (Qiagen) according to the manufacturer's instructions from formalin-fixed paraffin-embedded tissue sections. MYD88 mutations were studied in 16 mantle cell lymphoma cases, using an allele-specific PCR for the L265P mutation in 11 (7 SOX11-negative and 4 SOX11-positive cases) and sequencing exon 5 in 12 (6 SOX11-negative and 6 SOX11-positive cases). Seven cases were investigated with both approaches 
obtaining similar results. The protocol for analysis using an allele-specific PCR was previously described. ${ }^{35}$ MYD88 exon 5 was amplified with the primers forward: 5'-TGCCAGGGGTACTTAGATGG $-3^{\prime}$ and reverse 5'-GAAGTTGGCATCTCCAGGAA-3'. Sequences were analyzed with the Mutation Surveyor (Softgenetics).

\section{Results}

\section{Clinical Characteristics}

The main clinical and pathological characteristics of the patients are summarized in Table 1. The 19 SOX11-negative mantle cell lymphomas presented with a non-nodal disease more frequently than positive tumors (79 vs 20\% $P<0.001$ ). Leukemic expression was observed in 11/12 (92\%) SOX11negative and in $21 / 28(75 \%)$ positive cases. Bone marrow involvement was present in 100 vs $89 \%$ in SOX11-negative and -positive tumors, respectively (Table 1). No bone lytic lesions or hypercalcemia was reported in any of the cases. SOX11-negative cases had a more indolent clinical course, as fewer patients with this subtype of mantle cell lymphoma needed chemotherapy at diagnosis (36 vs $96 \%$ $P<0.001$ ) and the overall median survival was longer than in patients with SOX11-positive mantle cell lymphoma (103 months, range 64-141 vs 44 months, range $24-64, P=0.024$ ) (Figure 1).

\section{Histopathology}

All cases were diagnosed as mantle cell lymphoma based on their morphological and immunophenotypic features and were cyclin D1 and PAX5 positive (Table 1). SOX11-negative mantle cell lymphoma had small cell morphology in $58 \%$ of the cases,

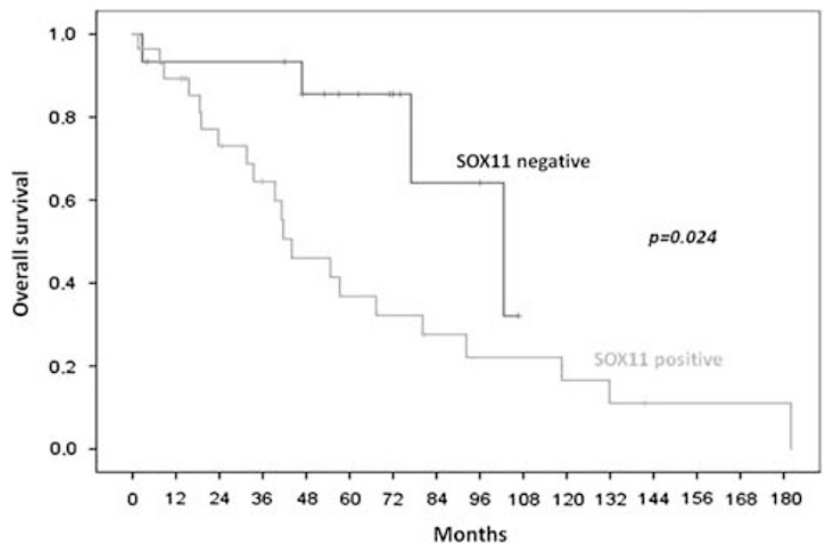

Figure 1 Overall survival in mantle cell lymphoma patients according to SOX11 expression. Overall median survival was longer in patients with SOX11-negative $(n=16)$ than SOX11positive $(n=28)$ mantle cell lymphoma (103 months $95 \%$ confidence interval 64-141 vs 44 months 95\% confidence interval 24-64) $(P=0.024)$. classical in $37 \%$, and blastoid in only one case (5\%) (Table 1). The cytological variants of SOX11-positive cases were classical in $81 \%$, small cell in $2 \%$, and blastoid in $17 \%$. The three SOX11-negative cases with nodal biopsies had preserved reactive germinal centers, whereas this feature was only observed in 8/29 SOX11-positive tumors with nodal presentation (100 vs $28 \% P=0.012$ ). Finally, the Ki67 proliferation index was significantly lower in the SOX11-negative than -positive cases $(20 \pm$ s.d. 18 vs $34.5 \pm$ s.d. 23 , $P=0.017$ ) (Table 1).

\section{Monotypic Plasma Cells in SOX11-Negative Mantle Cell Lymphoma}

Polytypic plasma cells were commonly seen in virtually all cases independently of SOX11 expression. However, a monotypic plasma cell population and variable number of lymphoid cells with plasmacytic differentiation were focally seen in 7 of the $19(37 \%)$ SOX11-negative but in none of the SOX11positive cases $(P<0.001)$. All these cases had an atypical lymphoid component that could be diagnosed as mantle cell lymphoma, classical in three cases, and small cell variant in four (Figure 2). The monotypic plasma cells were seen in three splenic, three nodal, and one periorbital tumors. Dutcher bodies were found in three of these cases. The monotypic plasma cells in the spleen formed small clusters and sheets with a peritrabecular and periarteriolar distribution (Figure 3). In the nodal and periorbital cases the plasma and lymphoplasmacytic cells were more intermingled with the atypical lymphoid cells. Interestingly, in nodal cases with persistent reactive germinal centers, monotypic plasma cells and cells with Dutcher bodies could be seen within the mantle zones (Figure 4).

All cells with plasmacytic differentiation, including the ones with Dutcher bodies, were cyclin D1 positive, supporting that they belonged to the same neoplastic population as the atypical lymphoid cells (Figure 4). The presence of the $t(11 ; 14)(q 13 ; q 32)$ was confirmed in the four of these seven cases in which it was examined. Five $(71 \%)$ cases expressed kappa and two expressed (29\%) lambda. IgM and IgD expression by immunohistochemistry was observed in three of four cases and three of five, respectively, whereas CD5 expression was observed in four of seven cases. Interesting, although the neoplastic populations of atypical lymphoid cells were PAX5 positive, the monotypic plasma cells were PAX5 negative (Figure 3). An elevated monoclonal IgM component in the serum was detected in three patients. Three of these seven cases in which the IGHV mutational status could be studied showed $>2 \%$ mutations. These seven cases had an indolent clinical evolution as none of them required chemotherapy for at least 2 years after diagnosis. 

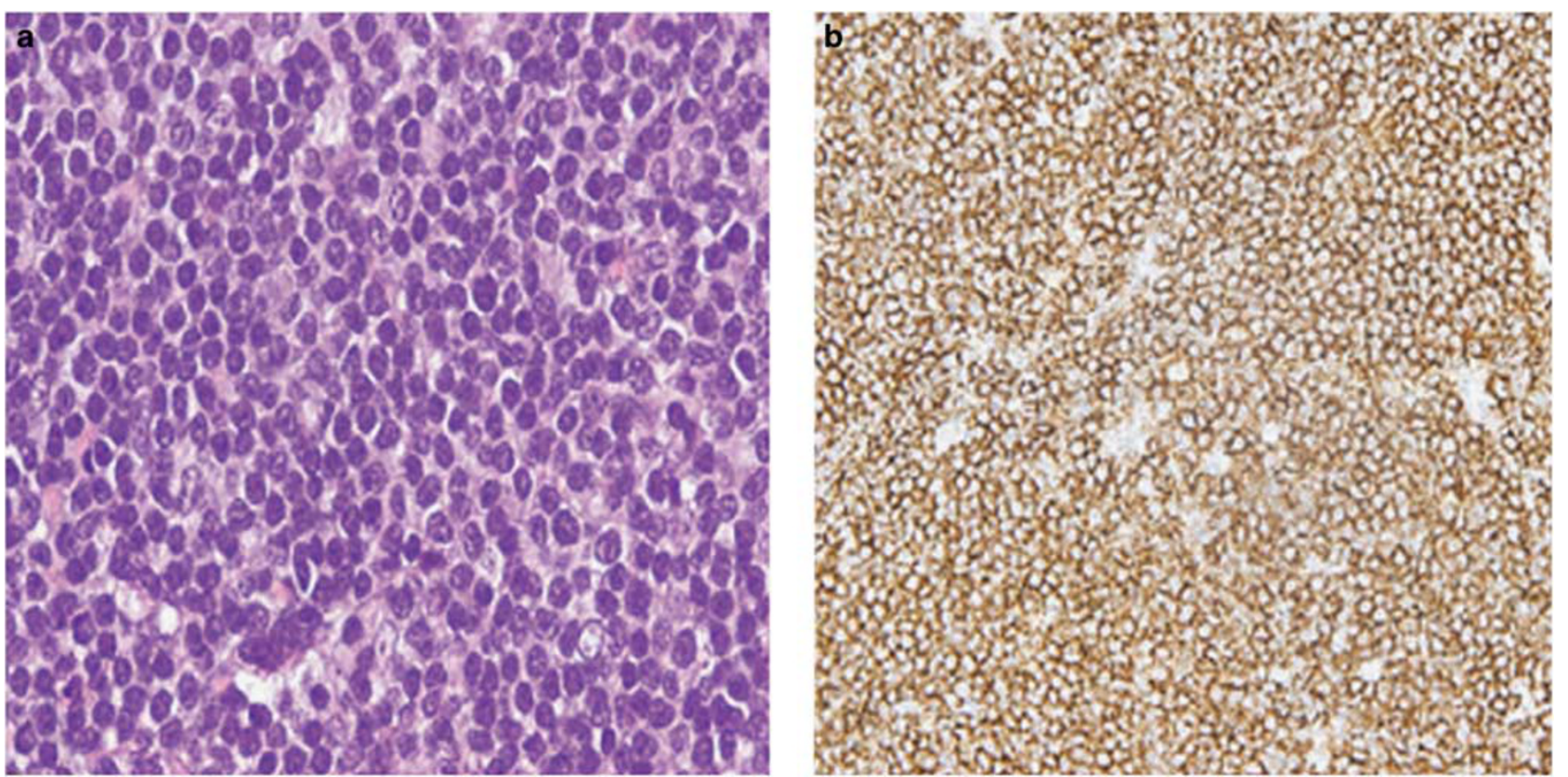

Figure 2 SOX11-negative mantle cell lymphoma with monotypic plasma cell showed a main component with small cell morphology. (a) H\&E, (b) CD20, (c) CD3, (d) CD5, (e) cyclin D1, (f) BLIMP1. H\&E, hematoxylin and eosin.

\section{Immunohistochemical Findings}

An intense cytoplasmic light-chain protein expression was seen in 11 of the 19 (58\%) SOX11-negative mantle cell lymphomas, including the 7 with monotypic plasma cells, but only in 5 of $39(13 \%)$ SOX11-positive tumors $(P=0.001)$ (Figure 5). Flow cytometry studies performed in cell suspensions of three of the seven SOX11-negative cases with plasmacytic cell differentiation confirmed the same surface kappa light chain restriction in lymphoid cells as the cytoplasmic light chain observed in the plasma cells by immunohistochemistry.

IRF4/MUM1 expression in $>10 \%$ of tumor cells was detected in 10/19 (53\%) SOX11-negative and in 18/40 (45\%) SOX11-positive tumors. No differences in the total number of positive cells in both subtypes of mantle cell lymphoma were seen (Figure 5). In addition to plasma and lymphoplasmacytic cells of the 7 SOX11-negative cases, atypical lymphoid cells were also frequently positive in both SOX11-negative and -positive tumors. IRF4/MUM1-positive cells tended to form clusters and large nodular aggregates in both subtypes of SOX11-negative and -positive tumors (Figure 5).

The expression of the plasmacytic transcription factor BLIMP1 was more frequently seen in SOX11negative than in -positive tumors (83 vs 34\% $P=0.001$ ) (Figure 2f and 5) (Table 1). The number of positive cells was variable among cases but was also higher in SOX11-negative (mean $26 \% \pm$ s.d. 23 ) than in -positive tumors (mean $13 \% \pm$ s.d. 19) $(P<0.04)$ (Figure 6a). BLIMP1 was not only expressed in plasma and lymphoplasmacytic cells but also in atypical lymphoid cells without morphological plasmacytic differentiation. Cases with high number of positive cells tend to have a diffuse distribution, whereas in cases with smaller number of cells they tended to concentrate in nodules.

Finally, to complete the assessment of plasmacytic differentiation we examined the expression of the transcription factor XBP1 (Figure 5). Similarly to BLIMP1, XBP1 nuclear expression was significantly more frequent in SOX11-negative than -positive mantle cell lymphomas ( 75 vs $11 \% \quad P<0.001)$ (Table 1). The mean value of the number of positive XBP1 tumor cells in SOX11-negative cases was also higher than in SOX11-positive tumors $(12 \% \pm$ s.d. 10 vs $3 \% \pm$ s.d. 4) $(P<0.004)$ (Figure 6b). The number of XBP1-positive cells was almost always lower than the BLIMP1 expressing cells but were found with a similar topographic distribution. Interestingly, whereas 11 of the 12 (92\%) cases considered positive for XBP1 also expressed BLIMP1 in the SOX11negative cases, only 1 of the 4 (25\%) SOX11-positive case expressed both proteins.

\section{MYD88 Mutations}

MYD88 mutations were studied in nine SOX11negative mantle cell lymphoma, including the seven cases with plasmacytic differentiation and in seven SOX11-positive cases. The MYD88 L256P mutation was only found in one SOX11-negative mantle cell lymphoma with plasmacytic differentiation (Figure 4). This case had areas of small atypical lymphoid cells consistent with mantle cell lymphoma, and cyclin D1 could be clearly demonstrated in 

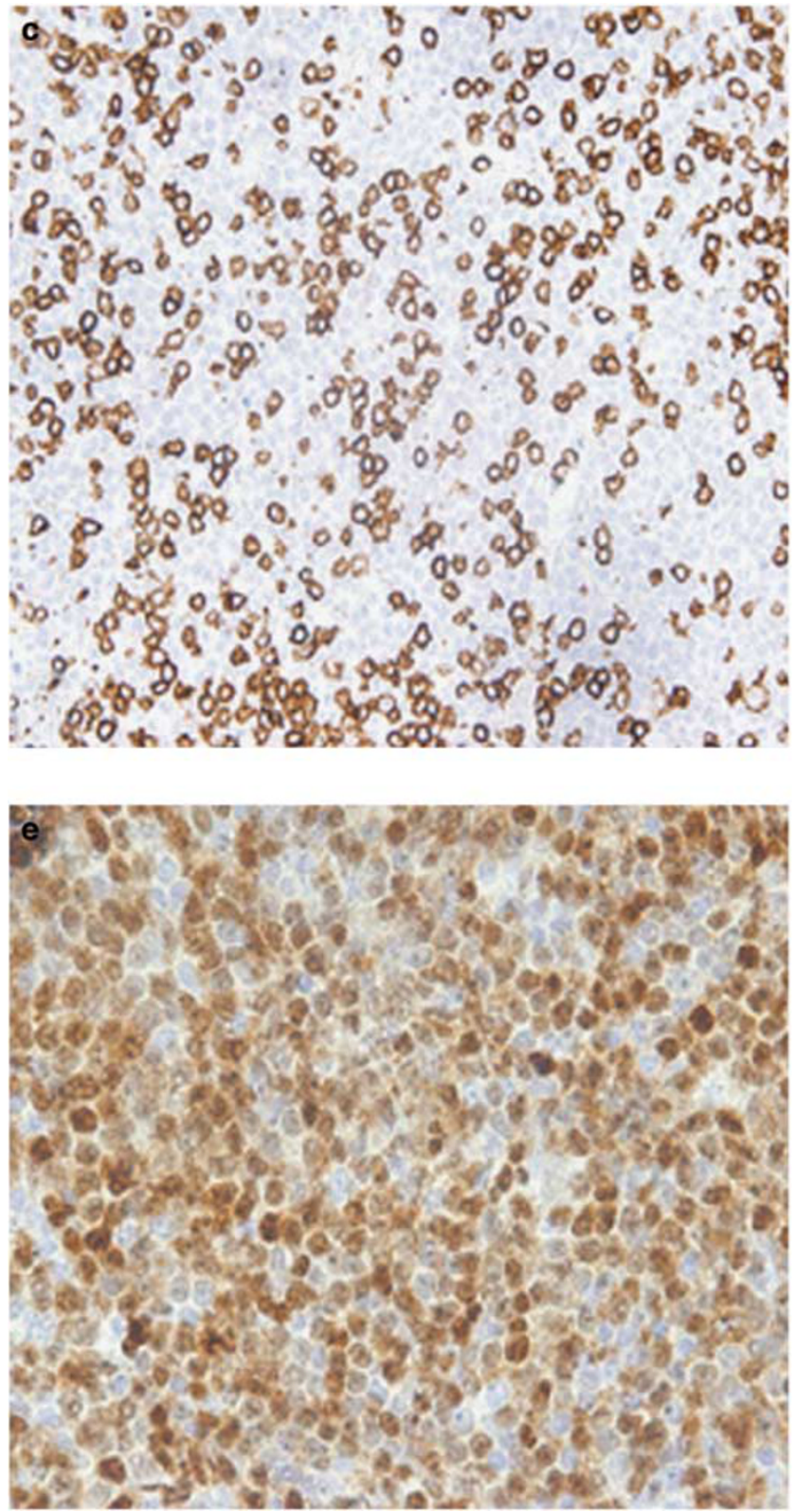

Figure 2 Continued.

plasma cells and cells with Dutcher bodies. The $\mathrm{t}(11 ; 14)$ (q13;q32) was demonstrated by FISH.

\section{Discussion}

Plasmacytic differentiation is a phenomenon seen in different types of small B-cell lymphomas with variable frequency. ${ }^{21,23}$ It constitutes an essential element in the definition of lymphoplasmacytic lymphoma and may be seen with different degree in marginal zone lymphoma, follicular lymphoma, and chronic lymphocytic leukemia. Classical mantle cell lymphoma has been considered as a tumor composed of a monotonous proliferation of small to
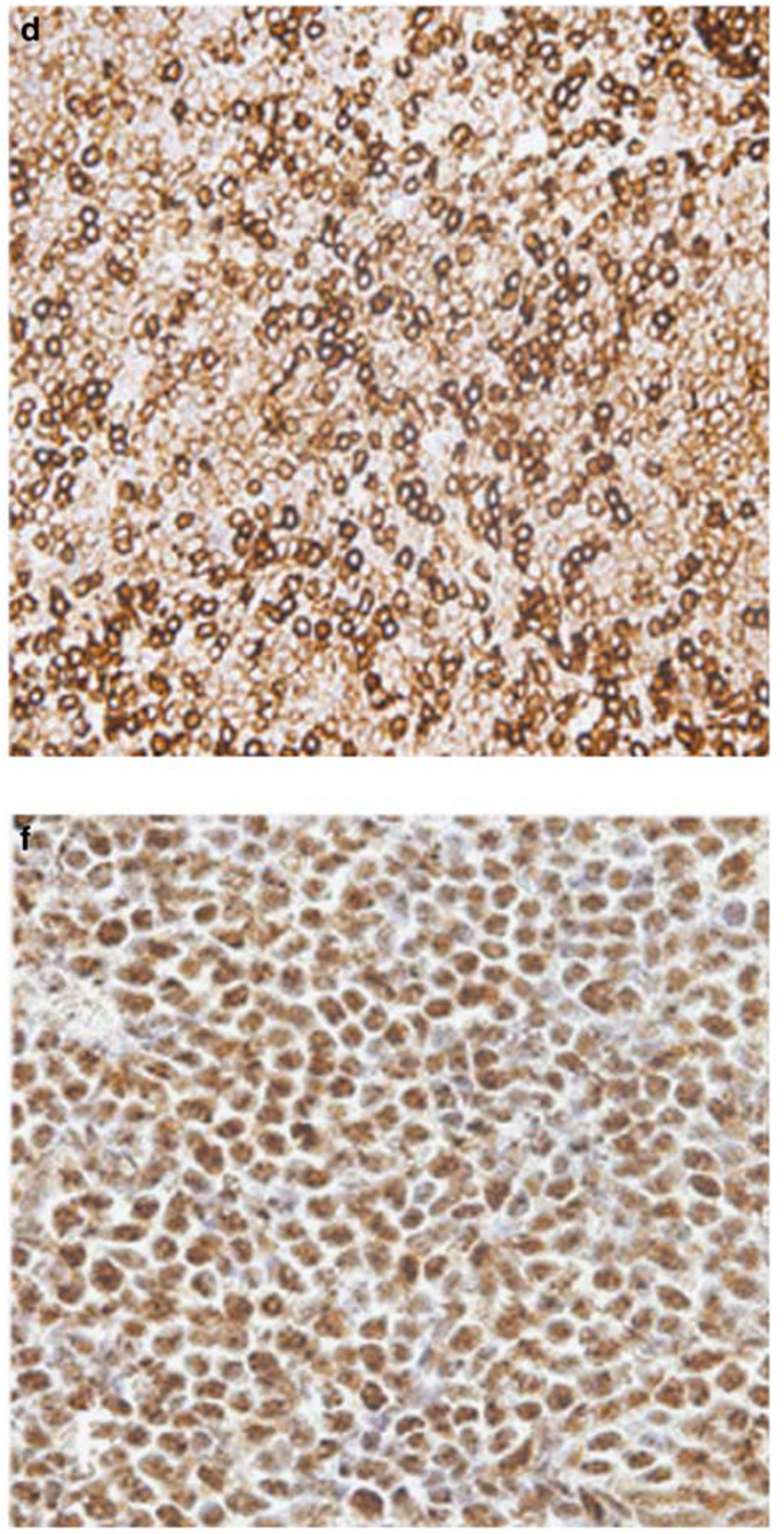

medium-sized lymphoid cells with irregular nuclei. Different morphological variants have been recognized such as blastoid and small cell. The small cell variant seen in $58 \%$ of our SOX11-negative tumors is composed of small lymphocytes with rounded nuclei, dense chromatin, and scanty cytoplasm mimicking small lymphocytic lymphoma. However, prolymphocytes, paraimmunoblasts or proliferation centers are never found in this variant. ${ }^{36}$

Contrary to other small B-cell lymphomas, plasmacytic differentiation is not usually found in mantle cell lymphoma. However, in recent years, several studies have reported occasional tumors with clonally related monotypic plasma cells. ${ }^{30-32,37}$ These cases are rare but have raised questions on the potential mechanisms 

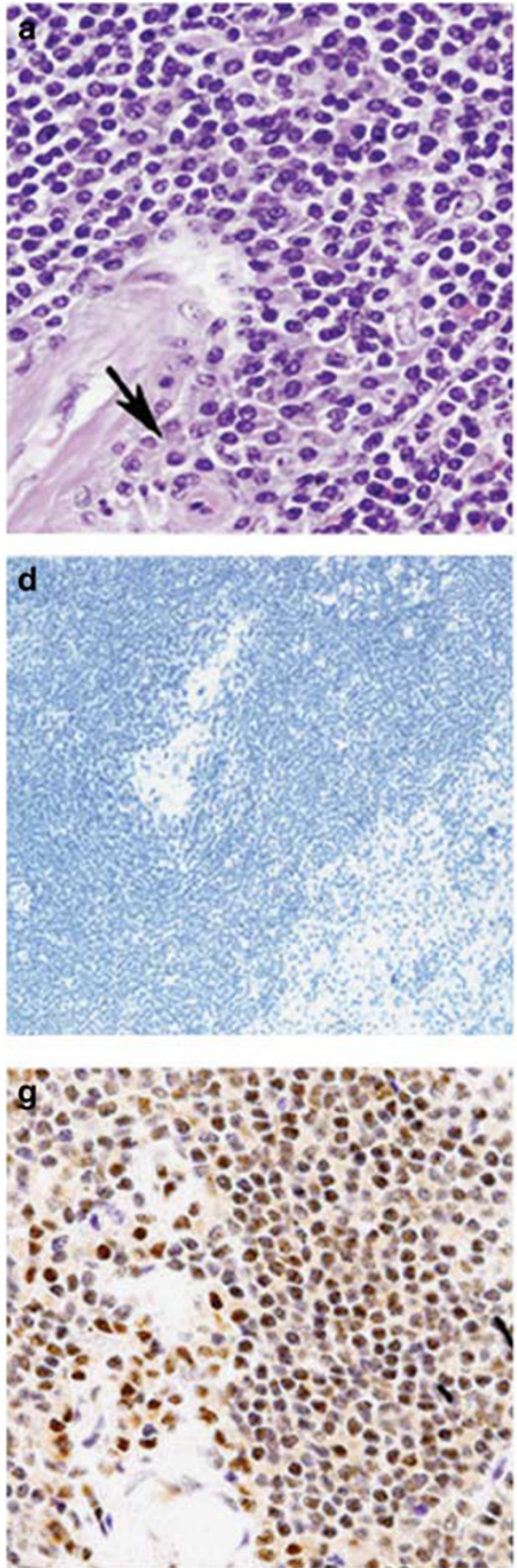
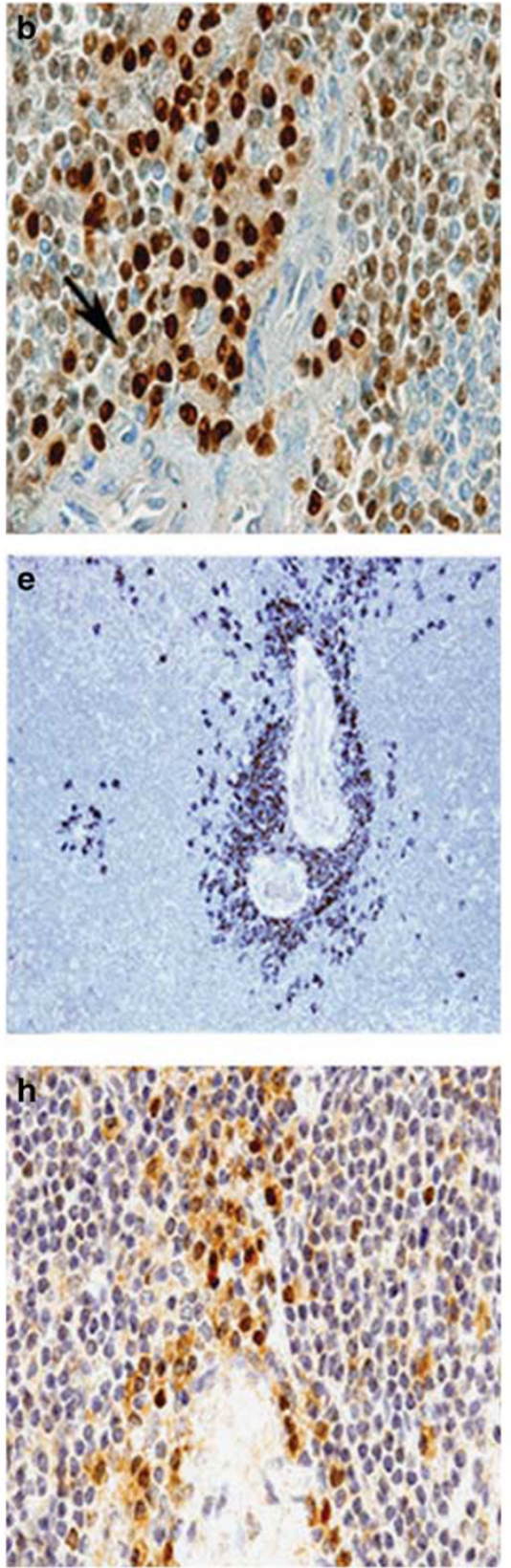
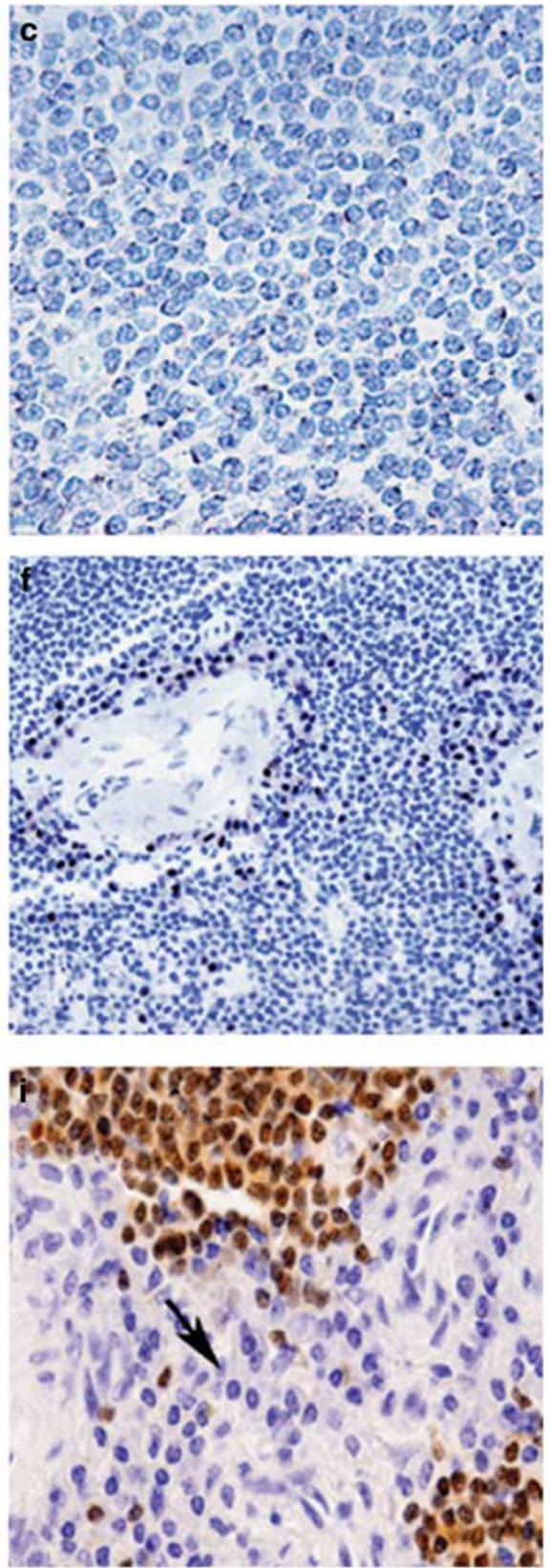

Figure 3 Plasma cell differentiation in mantle cell lymphoma: splenic SOX11-negative mantle cell lymphoma with a Lambda monotypic plasma cell population. (a) H\&E with black arrow indicating a periarteriolar plasma cell distribution, (b) cyclin D1 with black arrow indicating cyclin D1-positive plasma cells with periarteriolar distribution, (c) SOX11, (d) kappa, (e) lambda with a distinctive monotypic peritrabecular plasma cell distribution, (f) IRF4/MUM1, (g) BLIMP1, (h) XBP1, (i) PAX5 with black arrow indicating PAX5-negative periarteriolar plasma cell distribution. H\&E, hematoxylin and eosin.

involved in their terminal B-cell. This process is normally regulated by the coordinated action of several transcription factors including PAX5, IRF4/ MUM1, BLIMP1, and XBP1. ${ }^{14-17}$ PAX5 maintains the mature B-cell differentiation program and represses the expression of BLIMP1 required to turn on the plasma cell differentiation program by activating XBP1 among other factors. IRF4/MUM1 is initially expressed in a small number of germinal center cells committed to exit this microenvironment and progress toward plasma cells. The expression of these transcriptions factors in mantle cell lymphoma and their possible relationship to the plasma cell differentiation has not been investigated. In a recent experimental study we demonstrated that SOX11, a transcription factor expressed in $\sim 90 \%$ of mantle cell lymphomas, binds directly to the promoter region of PAX5 and regulates positively its expression that in turn represses BLIMP1 and blocks the terminal differentiation of mantle cell lymphoma cells. ${ }^{13}$ These observations made us hypothesize that plasma cell differentiation and upregulation of transcription 

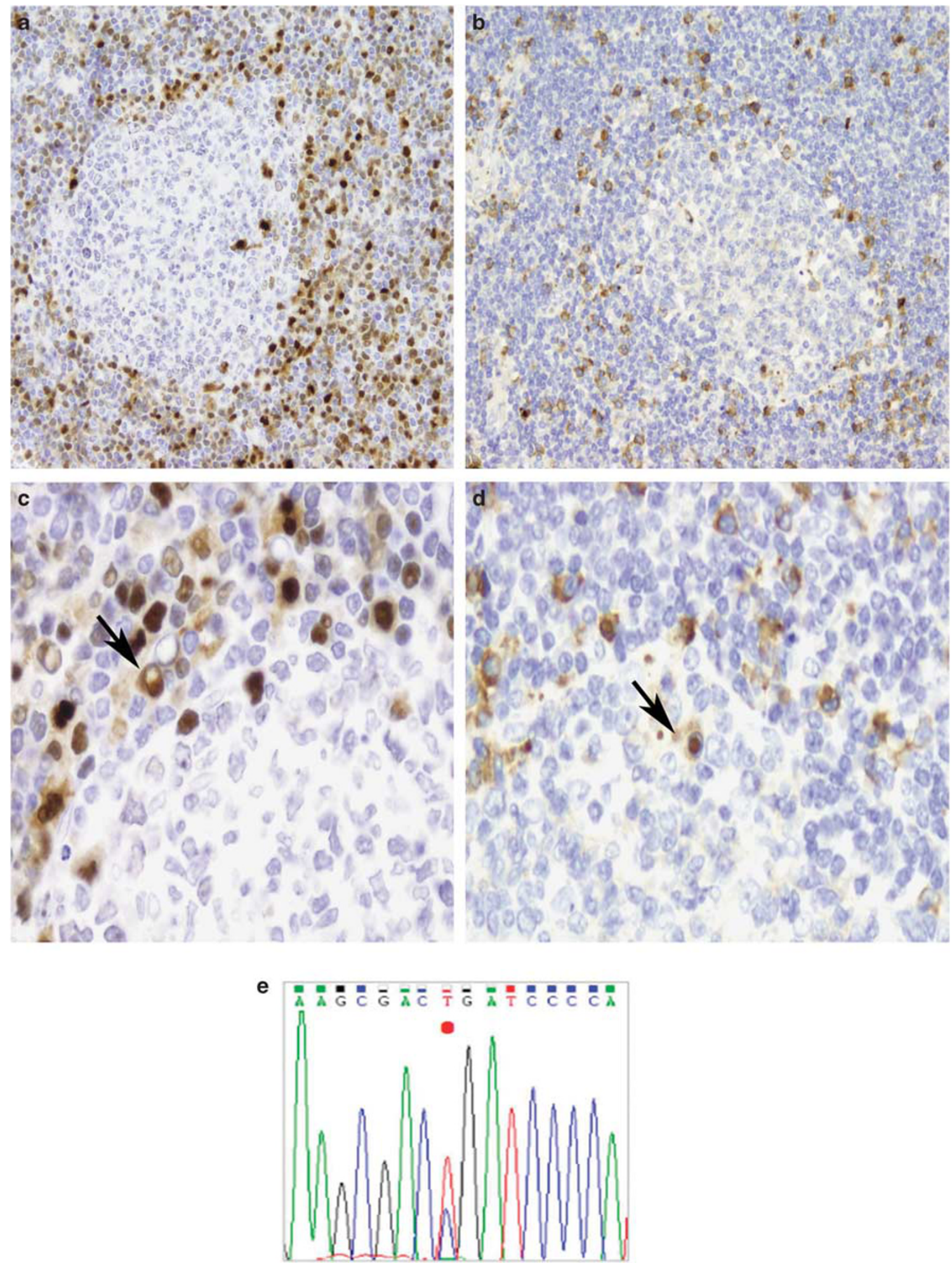

Figure 4 Lymphoplasmacytic cells with Dutcher bodies in cyclin D1-positive SOX11-negative mantle cell lymphoma. (a) Cyclin D1positive lymphoplasmacytic cells with mantle zone distribution, (b) kappa monotypic plasma cells with mantle zone distribution, (c) cyclin D1-positive cells with Dutcher bodies indicated by black arrow, (d) kappa monotypic Dutcher bodies indicated by black arrow, (e) Sanger sequencing of MYD88 mutation in SOX11-negative mantle cell lymphoma with plasmacytic differentiation.

factors related to the terminal B-cell differentiation program in mantle cell lymphoma could be a phenomenon mainly occurring in SOX11-negative tumors.
In the current study, we have identified the presence of monotypic plasma cells and lymphoid cells with plasmacytic features in 7 of 60 mantle cell 

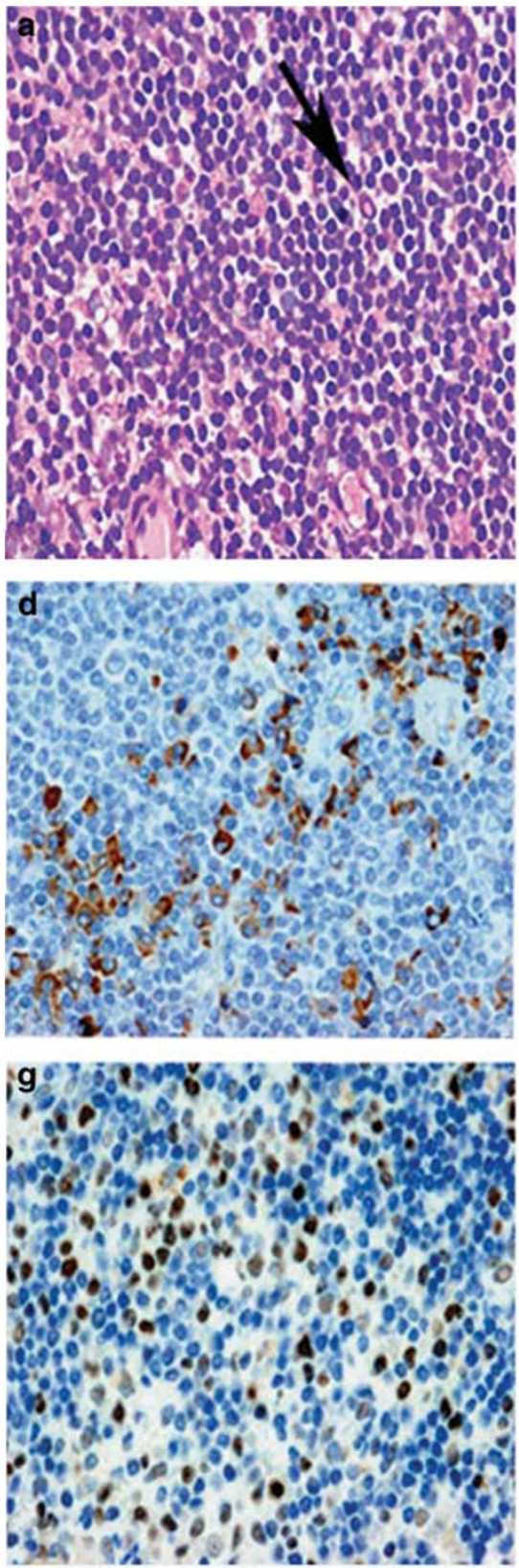
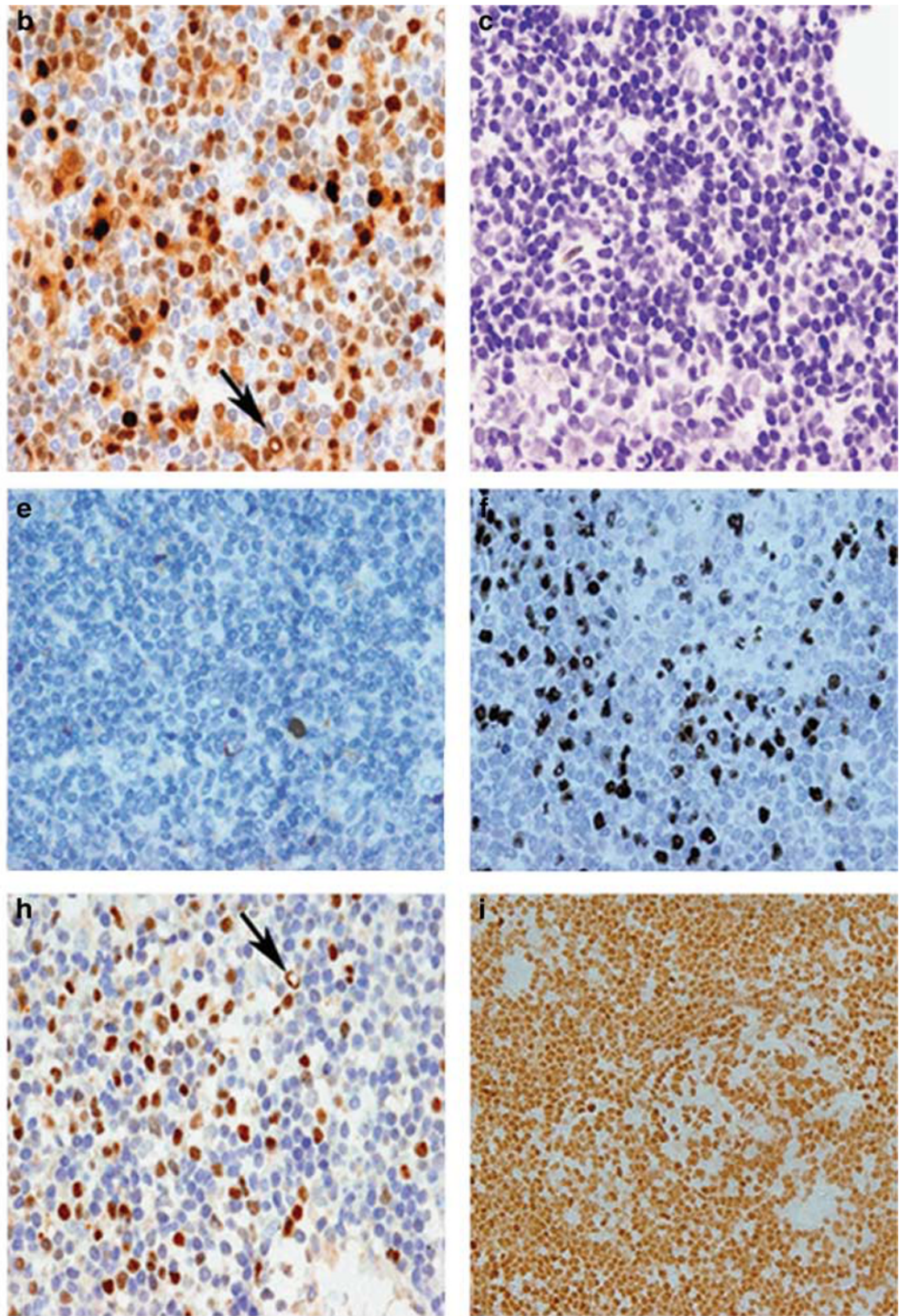

Figure 5 Cytoplasmic light chain expression, IRF4/MUM1, BLIMP1, and XBP1 expression in a SOX11-negative case. (a) H\&E with black arrow indicating Dutcher body, (b) cyclin D1 with black arrow indicating Dutcher body, (c) SOX11, (d) kappa, (e) lambda, (f) IRF4/MUM1, (g) BLIMP1, (h) XBP1 with black arrow indicating Dutcher body, (i) PAX5. H\&E, hematoxylin and eosin.

lymphomas. This incidence should not be considered representative, as some of these cases had been sent in consultation because of this unusual feature. CD5 positivity was observed in $57 \%$ and $\mathrm{IgD}$ expression in $60 \%$ of these cases. In all cases, the plasma and lymphoplasmacytic cells with Dutcher bodies had strong nuclear expression of cyclin D1 and in three cases in which flow cytometry was performed the atypical lymphoid cells expressed the same lightchain restriction than the plasma cells. These finding suggest that the monotypic plasma cells and mantle cell lymphoma cells belong to the same tumor. In one of these cases, the clonal relationship between plasma cells and mantle cell lymphoma cells had been previously demonstrated by molecularly investigating the IGH rearrangement. ${ }^{32}$ Interestingly, the seven cases with the plasma cell component were SOX11-negative, confirming the idea that the absence of this transcription factor may allow mantle cell lymphoma cells to progress in the terminal B-cell differentiation process.

The clinical and pathological presentations of these seven cases had similarities with the eight previous reported mantle cell lymphomas with clonal plasma cells. ${ }^{30-32,37}$ Most of these patients had nodal involvement but extranodal dissemination 

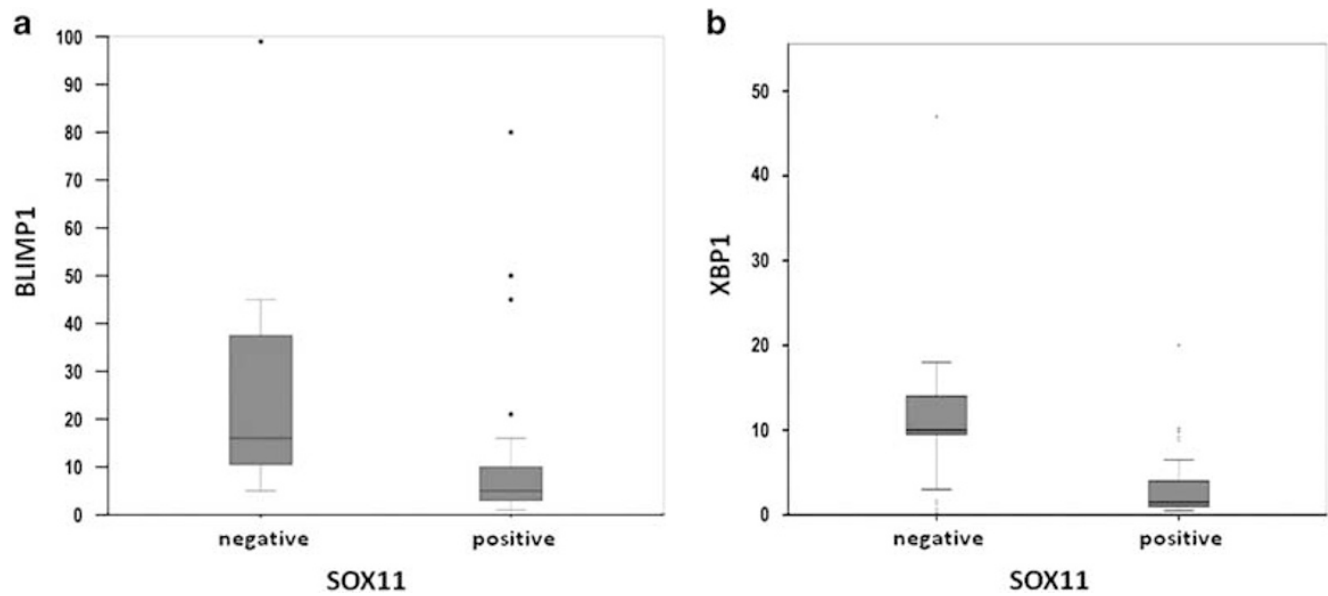

Figure 6 (a) Percentage of BLIMP1-positive cells in SOX11-negative and positive mantle cell lymphoma; (b) percentage of XBP1-positive cells in SOX11-negative and -positive mantle cell lymphoma.

was also frequent. One previous case had a periorbital presentation as one of our patients. ${ }^{32}$ Three cases had a mantle zone growth pattern and most cases had been cytologically considered classical mantle cell lymphoma except one pleomorphic variant. One previous case had an intriguing clonally related plasmablastic differentiation in the transformation of a classical mantle cell lymphoma. ${ }^{37}$ Interestingly, the three cases in which we could investigate the IGHV mutational status had a low level of identity with the germline $(<2 \%)$, indicating that these tumors derive from cells that have experienced the germinal center microenvironment, a feature also common in SOX11negative mantle cell lymphoma. ${ }^{38}$ The clinical course of these seven cases was indolent, as none of the patients required chemotherapy for at least 2 years, a behavior similar to that described in other SOX11negative mantle cell lymphomas. ${ }^{7-10}$

To expand the analysis of the terminal B-cell differentiation program in mantle cell lymphoma, we investigated the expression of cytoplasmic immunoglobulin light chains, IRF4/MUM1, BLIMP1, and XBP1. A restricted and intense cytoplasmic light chain was seen more commonly in SOX11-negative $(58 \%)$ than in -positive $(13 \%)$ cases. IRF4/MUM1 expression has been observed in $10-50 \%$ of mantle cell lymphoma without a clear relationship to particular clinical or pathological features of the tumors. ${ }^{39-42}$ The IRF4/MUM1 positivity in $47 \%$ of our cases is similar to these reports. In addition, we did not observe differences in the expression between SOX11-negative (53\%) and -positive (45\%) tumors. This finding in primary tumor samples is concordant with our previous experimental observation of the lack of modulation of IRF4/MUM1 by SOX11 silencing in mantle cell lymphoma cell lines, suggesting an independent regulation of these transcription factors in these tumors. ${ }^{13}$

BLIMP1 and XBP1 are expressed in plasma cell neoplasias and aggressive lymphomas with plasmablastic differentiation but their distribution in small
B-cell lymphomas has been less investigated. ${ }^{43}$ We found a relatively high expression of these transcriptions factors in mantle cell lymphoma and both of them were significantly more common in SOX11-negative than in -positive tumors. The knockdown of SOX11 by shRNA in mantle cell lymphoma cell lines leads to a downregulation of PAX5 and a switch toward the terminal B-cell differentiation program with increased expression of BLIMP1 and XBP1. ${ }^{13}$ Our BLIMP1 and $\mathrm{XBP} 1$ findings in primary SOX11-negative tumors are consistent with the observation in the experimental model. However, we did not see a clear downregulation of PAX5 in SOX11-negative tumors, although the monotypic plasma cells were PAX5 negative. PAX5 is expressed in all mature B-cell lymphomas and its regulation includes complex mechanisms. Our findings would be consistent with the idea that SOX11 expression may prevent the downregulation of PAX5 and the absence of this transcription factor may allow tumor cells to be more responsive to regulatory stimuli promoting terminal B-cell differentiation.

The differential diagnosis of small B-cell lymphomas with plasmacytic differentiation encompasses several entities. The general agreement is that these tumors must be classified according to the atypical lymphoid component. The identification of cyclin D1 expression or the $t(11 ; 14)(q 13 ; q 32)$ may facilitate the diagnosis of mantle cell lymphoma. However, given that plasmacytic differentiation in these tumors is rare. and some of these may be CD5-negative, the recognition of a small B-cell lymphoma with terminal B-cell differentiation as mantle cell lymphoma may be challenging. The presence of Dutcher bodies and a monoclonal component in the serum may suggest the diagnosis of lymphoplasmacytic lymphoma or less frequently marginal zone lymphoma. However, the clinical presentation with generalized lymphadenopathy and leukemic expression in some cases should raise the possibility of a mantle cell lymphoma. The recent identification of MYD88 mutations as a genetic hallmark of lymphoplasmacytic lymphoma may help 
in establishing this diagnosis, and its absence would favor a different small B-cell lymphoma. ${ }^{24,27}$ The same mutation has been reported in occasional cases of marginal zone lymphoma. However, although some genuine marginal zone lymphoma may carry the mutation, a positive result must be interpreted with caution. $^{27}$ MYD88 mutations have been also identified in 3\% of chronic lymphocytic leukemia and they seem to recognize a particular subgroup of young patients with good prognosis and without plasmacytic differentiation. ${ }^{28}$ The finding of the L256P MYD88 mutation in one of our mantle cell lymphoma with plasmacytic differentiation is surprising, as these mutations have been investigated in >100 mantle cell lymphomas and all had been negative and it was also negative in the remaining six cases with monotypic plasma cells in this study. ${ }^{44-48}$ In our MYD88mutated case cyclin D1 was unequivocally positive in plasma cells and cells with Dutcher bodies, and the tumor carried the $t(11 ; 14)(q 13 ; q 32)$ supporting the diagnosis of mantle cell lymphoma and excluding the existence of two different tumors. The consideration of this case as a real mantle cell lymphoma, or alternatively as a lymphoplasmacytic lymphoma or marginal zone lymphoma with the $t(11 ; 14)(q 13 ; q 32)$ may be debatable. However, MYD88 mutations seem to be less specific than the $\mathrm{t}(11 ; 14)(\mathrm{q} 13 ; \mathrm{q} 32)$ defining an entity and the tumor cells with plasmacytic differentiation had a distribution in the mantle zone of residual follicles highly suggestive of a mantle cell lymphoma pattern.

The differential diagnosis with plasma cell myeloma $\mathrm{t}(11 ; 14)(\mathrm{q} 13 ; \mathrm{q} 32)$ positive should be also considered. ${ }^{49,50}$ Recently, several studies have investigated SOX11 immunohistochemical expression in 56 cases of plasmacytoma/myeloma $(73 \%$ cyclin D1-positive and 27\% cyclin D1-negative) including 12 cyclin D1-positive cases, which presented also the $\mathrm{t}(11 ; 14)(q 13 ; q 32)$. No nuclear SOX11 expression was found in any of these cases. ${ }^{3,6,34,51,52}$ However, mantle cell lymphoma with plasmacytic differentiation in this and previous studies are CD5 positive in $57 \%$, and tend to present with generalized lymphadenopathy and leukemic involvement without lytic bone lesions, all of them unusual features in plasma cell myeloma.

In conclusion, our study supports the idea that SOX11-negative mantle cell lymphoma is a particular subtype of these tumors characterized by more frequent morphological and phenotypic terminal B-cell differentiation features that may be facilitated by the absence of this transcription factor. The recognition of these features expands the spectrum of small B-cell lymphomas with plasmacytic differentiation in which this subset of mantle cell lymphoma should be included.

\section{Acknowledgments}

This work was supported by the grant from MINECO Plan Nacional SAF12/38432 (EC), Generalitat de
Catalunya AGAUR 2014-SGR-795 (EC), AGAUR 2014SGR967 (to DC) and Red Temática de Investigación Cooperativa en Cáncer (RD12/0036/0036) (EC) and (RD12/0036/0004) (DC). EC is a researcher of the Academia 'Institució Catalana de Recerca i Estudis Avançats' (ICREA). DM was supported by Instituto de Salud Carlos III, 'Contratos de Formación en Investigación Río-Hortega' CM12/00054. AM is supported by Instituto de Salud Carlos III, European Regional Development Fund (ERDF) 'One way to Europe’ (FIS PI11/00907, PI14/00333).

\section{Disclosure/conflict of interest}

The authors declare no conflict of interest.

\section{References}

1 Jares P, Colomer D, Campo E. Molecular pathogenesis of mantle cell lymphoma. J Clin Invest 2012;122: 3416-3423.

2 Ek S, Dictor M, Jerkeman M et al. Nuclear expression of the non B-cell lineage Sox11 transcription factor identifies mantle cell lymphoma. Blood 2008;111: 800-805.

3 Dictor M, Ek S, Sundberg M et al. Strong lymphoid nuclear expression of SOX11 transcription factor defines lymphoblastic neoplasms, mantle cell lymphoma and Burkitt's lymphoma. Haematologica 2009; 94:1563-1568.

4 Salaverria I, Royo C, Carvajal-Cuenca A et al. CCND2 rearrangements are the most frequent genetic events in cyclin D1(-) mantle cell lymphoma. Blood 2013;121: 1394-1402.

$5 \mathrm{Xu} \mathrm{W,} \mathrm{Li} \mathrm{JY.} \mathrm{SOX11} \mathrm{expression} \mathrm{in} \mathrm{mantle} \mathrm{cell}$ lymphoma. Leuk Lymphoma 2010;51:1962-1967.

6 Mozos A, Royo C, Hartmann E et al. SOX11 expression is highly specific for mantle cell lymphoma and identifies the cyclin D1-negative subtype. Haematologica 2009;94:1555-1562.

7 Fernandez V, Salamero O, Espinet B et al. Genomic and gene expression profiling defines indolent forms of mantle cell lymphoma. Cancer Res 2010;70:1408-1418.

8 Ondrejka SL, Lai R, Smith SD et al. Indolent mantle cell leukemia: a clinicopathological variant characterized by isolated lymphocytosis, interstitial bone marrow involvement, kappa light chain restriction, and good prognosis. Haematologica 2011;96:1121-1127.

9 Espinet B, Ferrer A, Bellosillo B et al. Distinction between asymptomatic monoclonal B-cell lymphocytosis with cyclin D1 overexpression and mantle cell lymphoma: from molecular profiling to flow cytometry. Clin Cancer Res 2014;20:1007-1019.

10 Royo C, Navarro A, Clot G et al. Non-nodal type of mantle cell lymphoma is a specific biological and clinical subgroup of the disease. Leukemia 2012;26: 1895-1898.

11 Nygren L, Baumgartner Wennerholm S, Klimkowska M et al. Prognostic role of SOX11 in a population-based cohort of mantle cell lymphoma. Blood 2012;119: 4215-4223.

12 Ferrando AA. SOX11 is a mantle cell lymphoma oncogene. Blood 2013;121:2169-2170. 
13 Vegliante MC, Palomero J, Perez- Galan P et al. SOX11 regulates PAX5 expression and blocks terminal B-cell differentiation in aggressive mantle cell lymphoma. Blood 2013;121:2175-2185.

14 Nera KP, Kohonen P, Narvin E et al. Loss of Pax5 promotes plasma cell differentiation. Immunity 2006;24:283-293.

15 Shaffer AL, Lin KI, Kuo TC et al. Blimp-1 orchestrates plasma cell differentiation by extinguishing the mature B cell gene expression program. Immunity 2002;17: 51-62.

16 Kallies A, Hasbold J, Fairfax $\mathrm{K}$ et al. Initiation of Plasma-cell differentiation is independent of transcription factor Blimp-1. Immunity 2007;26:555-566.

17 Busslinger M, Klix N, Pfeffer P et al. Deregulation of PAX-5 by translocation of the Emu enhancer of the IgH locus adjacent to two alternative PAX-5 promoters in a diffuse large-cell lymphoma. Proc Natl Acad Sci USA 1996;93:6129-6134.

18 Pasqualucci L, Compagno M, Houldsworth $\mathrm{J}$ et al. Inactivation of the PRDM1/BLIMP1 gene in diffuse large B cell lymphoma. J Exp Med 2006;203:311-317.

19 Tam W, Gomez M, Chadburn A et al. Mutational analysis of PRDM1 indicates a tumor-suppressor role in diffuse large B-cell lymphomas. Blood 2006;107: 4090-4100.

20 Swerdlow SH, Campo E, Harris NL et al. WHO Classification of Tumors of Hematopoietic and Lymphoid Tissues, 4th (edn). IARC: Lyon, 2008, pp 194-195.

21 Lin P, Molina TJ, Cook JR et al. Lymphoplasmacytic lymphoma and other non-marginal zone lymphomas with plasmacytic differentiation. Am J Clin Pathol 2011;136:195-210.

22 Gradowski JF, Jaffe ES, Warnke RA et al. Follicular lymphomas with plasmacytic differentiation include two subtypes. Mod Pathol 2010;23:71-79.

23 Molina TJ, Lin P, Swerdlow SH et al. Marginal zone lymphomas with plasmacytic differentiation and related disorders. Am J Clin Pathol 2011;136:211-225.

24 Treon SP, Xu L, Yang G et al. MYD88 L265P somatic mutation in Waldenström's macroglobulinemia. N Engl J Med 2012;367:826-833.

25 Jiménez C, Sebastián E, Chillón MC et al. MYD88 L265P is a marker highly characteristic of, but not restricted to, Waldenström's macroglobulinemia. Leukemia 2013;27:1722-1728.

26 Ngo VN, Young RM, Schmitz R et al. Oncogenically active MYD88 mutations in human lymphoma. Nature 2011;470:115-119.

27 Hamadeh F, MacNamara SP, Aguilera NS et al. MYD88 L265P mutation analysis helps define nodal lymphoplasmacytic lymphoma. Mod Pathol 2014;28: 564-574.

28 Martínez-Trillos A, Pinyol M, Navarro A et al. Mutations in TLR/MYD88 pathway identify a subset of young chronic lymphocytic leukemia patients with favorable outcome. Blood 2014;123:3790-3796.

29 Lennert K, Mohri N, Stein H et al. Malignant Lymphomas other than Hodgkin's disease. Histology-CytologyUltrastructure-Immunology. Springer-Verlag: Berlin Heidelberg: New York, 1978, pp 281-301.

30 Young KH, Chan WC, Fu K et al. Mantle cell lymphoma with plasma cell differentiation. Am J Surg Pathol 2006;30:954-961.

31 Naushad H, Choi WW, Page CJ et al. Mantle cell lymphoma with flow cytometric evidence of clonal plasmacytic differentiation: a case report. Cytometry B Clin Cytom 2009;76:218-224.

32 Visco C, Hoeller S, Malik JT et al. Molecular characteristics of mantle cell lymphoma presenting with clonal plasma cell component. Am J Surg Pathol 2011;35: 177-189.

33 Perez-Galan $\mathrm{P}$, Mora-Jensen $\mathrm{H}$, Weniger MA et al. Bortezomib resistance in mantle cell lymphoma is associated with plasmacytic differentiation. Blood 2011;117:542-552.

34 Soldini D, Valera A, Sole C et al. Assessment of SOX11 expression in routine lymphoma tissue sections, characterization of new monoclonal antibodies for diagnosis of mantle cell lymphoma. Am J Surg Pathol 2014;38:86-93.

$35 \mathrm{Xu} \mathrm{L}$, Hunter ZR, Yang G et al. MYD88 L265P in Waldenström macroglobulinemia, immunoglobulin $\mathrm{M}$ monoclonal gammopathy, and other B-cell lymphoproliferative disorders using conventional and quantitative allele-specific polymerase chain reaction. Blood 2013;121:2051-2058.

36 Jaffe ES, Harris NL, Vardiman JW et al. Hematopathology, 1st (edn). Saunders/Elsevier: Philadelphia, 2011, pp 333-348.

37 Cooper CL, Joshua DE, Lee CS et al. Extranodal plasmablastic lymphoma arising in mantle cell lymphoma. Histopathology 2007;51:856-859.

38 Navarro A, Clot G, Royo C et al. Molecular subsets of mantle cell lymphoma defined by the IGHV mutational status and SOX11 expression have distinct biologic and clinical features. Cancer Res 2012;72:5307-5316.

39 Falini B, Fizzotti M, Pucciarini A et al. A monoclonal antibody (MUM1p) detects expression of the MUM1/ IRF4 protein in a subset of germinal center B cells, plasma cells, and activated T cells. Blood 2000;95: 2084-2092.

40 Martinez A, Pittaluga S, Rudelius M et al. Expression of the interferon regulatory factor $8 / \mathrm{ICSBP}-1$ in human reactive lymphoid tissues and B-cell lymphomas: a novel germinal center marker. Am J Surg Pathol 2008;32:1190-1200.

41 Natkunam Y, Warnke RA, Montgomery K et al. Analysis of MUM1/IRF4 protein expression using tissue microarrays and immunohistochemistry. Mod Pathol 2001;14:686-694.

42 Gualco G, Weiss LM, Harrington WJ Jr et al. BCL6, MUM1, and CD10 expression in mantle cell lymphoma. Appl Immunohistochem Mol Morphol 2010;18:103-108.

43 Montes-Moreno S, Gonzalez-Medina AR, RodriguezPinilla SM et al. Aggressive large B-cell lymphoma with plasma cell differentiation: immunohistochemical characterization of plasmablastic lymphoma and diffuse large B-cell lymphoma with partial plasmablastic phenotype. Haematologica 2010;95:1342-1349.

44 Ondrejka SL, Lin JJ, Warden DW et al. MYD88 L265P somatic mutation: its usefulness in the differential diagnosis of bone marrow involvement by B-cell lymphoproliferative disorders. Am J Clin Pathol 2013;140:387-394.

45 Beà S, Valdés-Mas R, Navarro A et al. Landscape of somatic mutations and clonal evolution in mantle cell lymphoma. Proc Natl Acad Sci USA 2013;110: 18250-18255.

46 Poulain S, Roumier C, Decambron A et al. MYD88 L265P mutation in Waldenstrom macroglobulinemia. Blood 2013;121:4504-4511. 
47 Capaldi IB, May AM, Schmitt-Graeff A et al. Detection of MYD88 L265P mutations in formalin-fixed and decalcified BM biopsies from patients with lymphoplasmacytic lymphoma. Exp Mol Pathol 2014;97:57-65.

48 Zhang J, Jima D, Moffitt $\mathrm{AB}$ et al. The genomic landscape of mantle cell lymphoma is related to the epigenetically determined chromatin state of normal B cells. Blood 2014;123:2988-2996.

49 Fonseca R, Blood EA, Oken MM et al. Myeloma and the $\mathrm{t}(11 ; 14)(\mathrm{q} 13 ; \mathrm{q} 32)$; evidence for a biologically defined unique subset of patients. Blood 2002;99:3735-3741.
50 King RL, Howard MT, Hodnefield JM et al. IgM multiple myeloma: pathologic evaluation of a rare entity. Am J Clin Pathol 2013;140:519-524.

51 Chen YH, Gao J, Fan G et al. Nuclear expression of sox11 is highly associated with mantle cell lymphoma but is independent of $t(11 ; 14)(q 13 ; q 32)$ in non-mantle cell B-cell neoplasms. Mod Pathol 2010;23:105-112.

52 Zhang YH, Liu J, Dawlett $\mathrm{M}$ et al. The role of SOX11 immunostaining in confirming the diagnosis of mantle cell lymphoma on fine-needle aspiration samples. Cancer Cytopathol 2014;122:892-897. 